\title{
EBW and LBW of Additive Manufactured Ti6Al4V Products
}

\author{
The weld bead geometry of powder bed additive manufactured \\ titanium alloys differed significantly from that of wrought material
}

\author{
BY B. TAVLOVICH, A. SHIRIZLY, AND R. KATZ
}

\begin{abstract}
This study investigated the weld joint properties of additive manufactured (AM) titanium parts. The welding experiments were performed using 4-kW fiber laser beam welding (LBW) and 30-kW, 80-kV electron beam welding (EBW). Wrought Ti6Al4V welded parts were compared to AM welded parts. In addition, the combination of welding AM parts to wrought (Ti6Al4V) parts was examined. The welds were analyzed and compared in terms of weld bead profile, tensile strength, microhardness, macro examination, and nondestructive testing. The results revealed certain differences between the welds of AM parts and the welds of wrought parts. Significant differences were found in the weld fusion zone (FZ) and in the material's thermal conductivity below the $\beta$ transus. The FZ boundary on the AM side of the joint was wider and had a straight shape versus the neck-shaped FZ boundary on the wrought material side. A thermal finite element model was used to simulate LBW. The simulation supported the experimental observations. The results indicate it is possible to achieve good-quality welds of AM to AM, and of AM to wrought material, for aerospace applications using both EBW and LBW.
\end{abstract}

\section{KEYWORDS}

- Laser Beam Welding • Electron Beam Welding • Ti6Al4V

- Additive Manufacturing - Thermal Conductivity

\section{Introduction}

Additive manufacturing (AM) is a relatively new type of manufacturing technology. Unlike the conventional machining technique that involves material removal, with AM technology, a digital 3D design data set is applied to build up material layer by layer. A high power source is used to melt a fine powder form, stacking layers until the $3 \mathrm{D}$ part is built. This $3 \mathrm{D}$ printing process does not require the use of fixtures, cutting tools, coolants, or other auxiliary resources (Ref. 1). Thus, AM enables high geometrical flexibility in the manufacturing process and facilitates the construction of components with highly complex shapes. The complex part can be extremely light, with features that are difficult or even impossible to obtain using any conventional manufacturing technique (turning, milling, etc.). Once the process is complete, the part can be removed from the machine's base platform. In most cases, additional postprocessing operations are required, such as support structure removal, heat treatment, and surface finishing (Ref. 2).

Because AM has become a competitive manufacturing technique in terms of cost, speed, reliability, and accuracy, it is marked as a "next generation" technology (Ref. 3). Nevertheless, the AM technology currently has some drawbacks, particularly with regard to surface finish as well as part-size limits due to the build chamber size (Ref. 4). In powder bed fusion (PBF) systems, the build envelope is an enclosed chamber that can be operated in a vacuum or filled with an inert gas to prevent the oxidation of reactive metal powders such as titanium or aluminum (Ref. 5). The PBF system size limits preclude the manufacturing of large parts in one piece. An alternative option is to build subparts separately and then weld them together in a postprocessing stage. Only a few studies in the scientific literature address the mechanical and metallurgical properties of AM welds (Refs. 6-10).

Matilainen et al. (Ref. 6) investigated the weldability aspects of 316L stainless steel by comparing bead-on-plate welds between selective laser melting (SLM) and cold-rolled (CR) sheet metal parts. They concluded that SLM manufactured parts can be welded with good-quality results. Their study showed that laser beam welding (LBW) of SLM stainless steel differed slightly from LBW of CR stainless steel; when the energy input was low, complete joint penetration could be achieved in the SLM material. However, when the weld lacked penetration, large pores were found in the SLM material welds. In addition, increased energy input affected the weld-cracking tendency in SLM material.

Wits and Becker (Ref. 7) compared pulsed LBW of Ti6Al4V AM parts vs. wrought parts. They concluded that LBW process parameters could not simply be transferred from wrought to AM parts. For the latter, more induced energy per unit weld length should be applied to obtain an identical weld geometry. Wits and Becker explained that this effect resulted from material consistency and imperfections due to the AM process. 
Table 1 - Chemical Composition of the Ti6Al4V Powder

\begin{tabular}{llllllllll} 
Element (\%)/Powder & $\mathrm{Al}$ & $\mathrm{V}$ & $\mathrm{Fe}$ & $\mathrm{O}$ & $\mathrm{C}$ & $\mathrm{N}$ & $\mathrm{H}$ & $\mathrm{Y}$ & $\mathrm{Ti}$ \\
\hline Powder 10-45 $\mu \mathrm{m}$ & 6.34 & 4.22 & 0.17 & 0.10 & 0.013 & 0.015 & 0.002 & $<0.001$ & Rem \\
ASTM F2924 & $5.50-$ & $3.50-$ & 0.30 & 0.20 & 0.08 & 0.05 & 0.015 & 0.005 & Rem \\
Requirements & 6.75 & 4.50 & max. & max. & max. & max. & max. & max. \\
\hline
\end{tabular}

Casalino et al. (Ref. 8) studied the effects of hybrid-laser gas tungsten arc welding (GTAW) of wrought austenitic stainless steel to AM SLM stainless steel. A sound weld was made using the laser-leading configuration. The microhardness of the annealed steels was $70 \mathrm{HV}$ lower than that of SLM steels. Tensile tests showed the tested AM welds had a higher tensile strength and a lower elongation than similar welds in wrought material of the same composition.

Nahmany et al. (Ref. 9) investigated electron beam autogenously welded AlSi10Mg samples produced by the SLM AM method. Two main differences were observed when comparing the EB-welded AM parts to the EB-welded cast samples: weld metal porosity and a negligible heat-affected zone (HAZ) in the AM joints, and a low porosity level but a substantial HAZ in the welded cast parts.

Prashanth et al. (Ref. 10) investigated the effect of friction welding (FW) on Al-12Si parts produced by SLM. The tensile strength experiments revealed the yield strength of the friction-welded SLM sample was $~ 45 \mathrm{MPa}$ lower than that of the SLM sample. However, the ductility increased from $\sim 3 \%$ in the as-built SLM case to $\sim 10 \%$ after FW. The cast samples displayed an opposite behavior. Those findings demonstrated that solid-state FW could be successfully used to join materials produced by SLM, and helped to significantly improve their ductility.

Tensile properties of Ti6Al4V fabricated by a number of AM techniques show strength levels superior to or comparable with conventional manufactured parts (cast, forged, and wrought annealed). As-built materials in laser-based processes exhibit less ductility; however, the ductility can be improved through a subsequent hot isostatic pressing and/or a heat treatment operation (Ref. 11).

The welding of titanium alloys is challenging and complicated. When the material is heated to above $\sim 550^{\circ} \mathrm{C}$, there is a strong reaction tendency with atmospheric gases or elements such as hydrogen, oxygen, nitrogen, or carbon. Once the metal surface has been contaminated, the rewelding process is no longer efficient since there is no way to get rid of the contaminated volume of metal. The incidental elements will cause severe embrittlement of the alloy and reduce its ductility and toughness, while increasing its strength and hardness (Refs. 12,13). Discoloration of the surface of the weld, or of the metal adjacent to the weld or on the back side of the weld, is indicative of the presence of oxygen. The discoloration of the weld metal can be used as an indicator of the shielding adequacy. This discoloration is directly related to the degree of weld metal embrittlement and hardness of the weld metal. However, it is imperative the weld bead discoloration not be utilized as an inspection tool for shielding adequacy, as the discoloration sequence will repeat itself as the oxidation thickness increases (Ref. 14).

Balasubramanian at el. (Ref. 13) presented GTAW as the preferred welding method for reactive materials, like titanium alloys, because of its comparatively easy applicability and better economy. However, for applications that require high-quality welds, as in aerospace or biomedical applications, LBW and electron beam welding (EBW) are the preferred welding methods. A main drawback of GTAW is its high-heat input and the resultant greater distortion and higher risk of contamination. High-energy beam techniques such as LBW or EBW are used to avoid these drawbacks. The main advantages of the LBW and EBW processes are their relatively low-heat input and high welding speed. Additionally, the LBW and EBW profiles are relatively narrow and deep, and have a small HAZ .

EBW is the natural choice for use with materials susceptible to oxidation, such as titanium. EBW operates in a highvacuum environment that shields the hot metal from contamination during the joining process (Refs. 13, 15, 16). On the other hand, LBW can be performed under atmospheric pressure, and its fiber-optic delivery provides increased flexibility compared to EBW (Ref. 14). To avoid embrittlement in LBW, titanium alloys are ordinarily shielded with a highpurity inert gas; argon and helium are the only shielding gases that should be considered when laser welding titanium alloys.

The goal of this study was to verify that the Ti6Al4V parts produced using the AM process can be reliably welded among themselves and to parts produced from a wrought Ti6Al4V. Two welding processes were evaluated: EBW and LBW. We concentrated on welding butt joint configurations using wrought manufactured samples, AM manufactured samples, and a combination of both. The wrought samples were manufactured from extruded rod, whereas the AM parts were manufactured by SLM. The EBW and LBW welds were compared in terms of weld bead profile, tensile strength, hardness, macro examination, and nondestructive testing.

\section{Experimental Procedures}

\section{Materials Used in This Study}

In the experimental part of this work, the weldability of wrought Ti6Al4V (annealed condition with an $\alpha / \beta$ microstructure) and of AM Ti6Al4V (with an $\alpha^{\prime}$ microstructure) were compared. The wrought test parts were manufactured by turning. The AM test parts were manufactured by SLM using a $30-\mu \mathrm{m}$ Ti6Al4V powder whose chemical composition is given in Table 1, corresponding to the ASTM F2924 standard (Ref. 17).

The chemical compositions of both wrought and AM Ti6Al4V weld specimens were measured according to the AMS 4904 standard (Ref. 18). The chemical composition of 


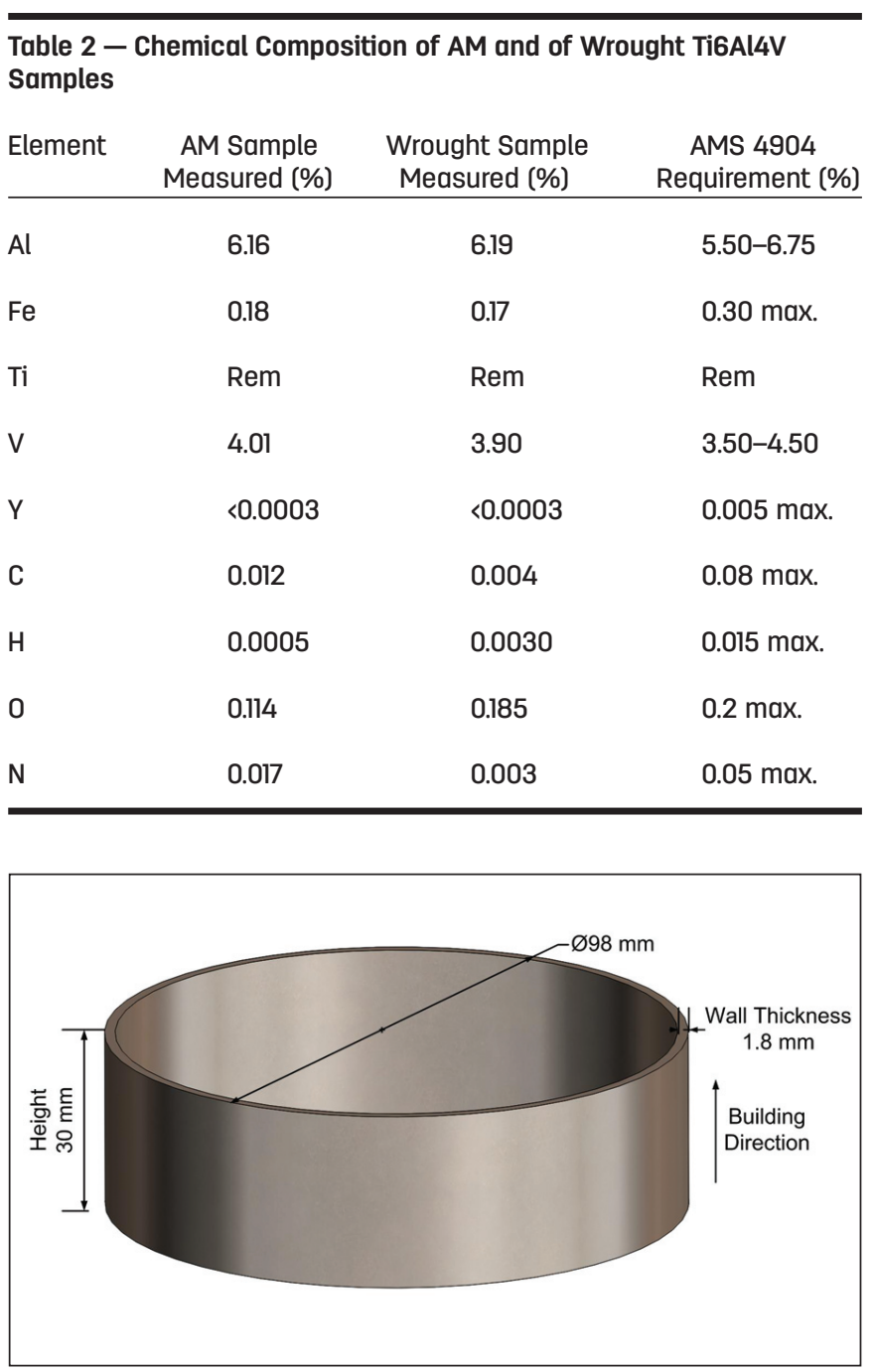

Fig. 1 - Test piece dimensions.

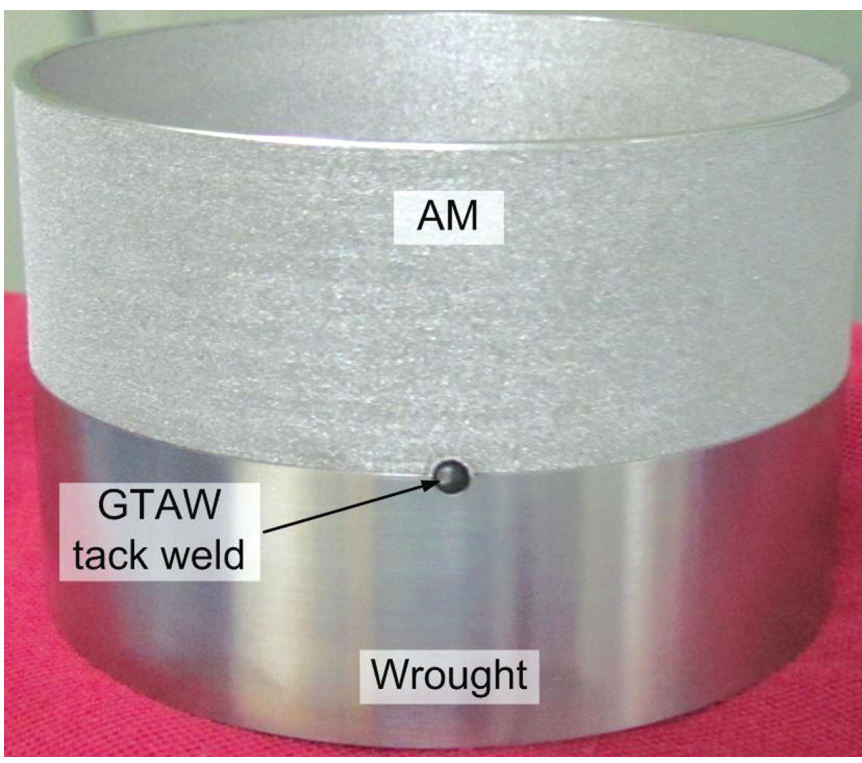

Fig. 2 - Tack-welded sample.

\begin{tabular}{|c|c|c|}
\hline Group Name & Manufacturing Process & Type of Weld \\
\hline $\mathrm{I}$ & AM & Not welded \\
\hline II & Wrought & Not welded \\
\hline III & AM & LBW \\
\hline IV & AM & EBW \\
\hline V & Wrought & LBW \\
\hline VI-1 & Wrought + surface machined after weld & EBW \\
\hline VI-2 & Wrought & EBW \\
\hline VII & AM to wrought & LBW \\
\hline VIII & AM to wrought & EBW \\
\hline IX & AM + surface machined before weld & LBW \\
\hline
\end{tabular}

the materials is presented in Table 2, and meets the AMS 4904 standard requirements.

\section{Part Geometry}

AM and wrought manufactured specimens of similar dimensions were produced, as shown in Fig. 1. AM samples were manufactured using an EOSINT M280 machine, with a 200-W Yb-fiber laser. The scan pattern used was of $8-\mathrm{mm}$ strips with a 67.5-deg rotation between adjacent layers. The building direction is indicated in Fig. 1 . The AM parts were stress relieved in a vacuum for $3 \mathrm{~h}$ at $650^{\circ} \mathrm{C}$.

\section{Preweld Sample Preparation}

All samples were chemically etched (etching oxide: $\mathrm{HNO}_{3}$ $370 \mathrm{gr} / \mathrm{L}, \mathrm{HF} 30 \mathrm{gr} / \mathrm{L}$ for $5 \mathrm{~min}$ ) to prevent any weld porosity as a result of contamination. The time interval between welding and etching was kept at a minimum and did not exceed 40 h (Ref. 19) to prevent oxidation. Prior to welding, it is common practice to clean the parts with a cheesecloth soaked with acetone. For AM parts, however, cleaning with a cheesecloth is not recommended due to the high surface roughness. The cheesecloth fibers tend to remain attached to the AM parts and may cause porosity; therefore, one should rely on the etching process. After etching, the samples were tack welded using GTAW, as seen in Fig. 2, and divided into groups, as shown in Table 3.

\section{Laser Beam Welding of the Test Parts}

The IPG Ytterbium fiber laser system YLS-4000-CT-WW was used for the LBW tests. To prevent titanium oxidation during the welding process, a special shielding gas protection jig was developed and applied as shown in Fig. 3.

Argon was used as a shielding gas, with flow rates of 30 $\mathrm{L} / \mathrm{min}$ through the nozzle, $18 \mathrm{~L} / \mathrm{min}$ between the jig cover tube and the external side of the tube specimen, and an in- 


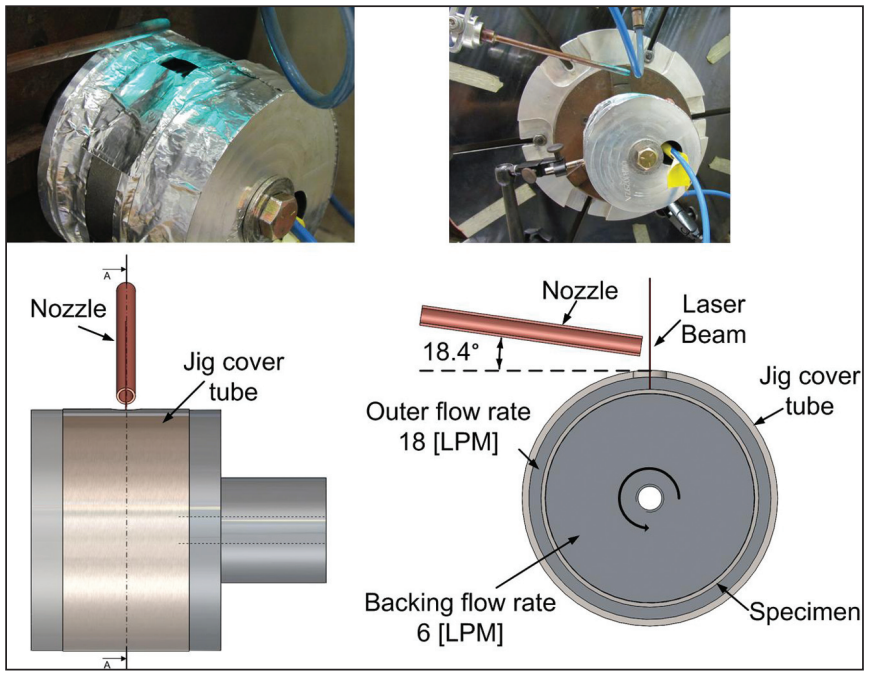

Fig. 3 - Laser beam jig welding setup with weld joint protected by inert gas to prevent oxidation.

ternal flow rate of $6 \mathrm{~L} / \mathrm{min}$ in the inner side of the tube specimen. The welding parameters used during welding are presented in Table 4.

To configure the welding mode, the power density and the aspect ratio (AR) for each LBW configuration was calculated as shown in Equations 1 and 2 (Ref. 20).

$$
\begin{gathered}
I=\frac{P_{\text {out }}}{A}=\frac{3000}{\pi \cdot w^{2} / 4}\left[\frac{W}{\mathrm{~mm}^{2}}\right] \\
A R=\frac{p}{w}
\end{gathered}
$$

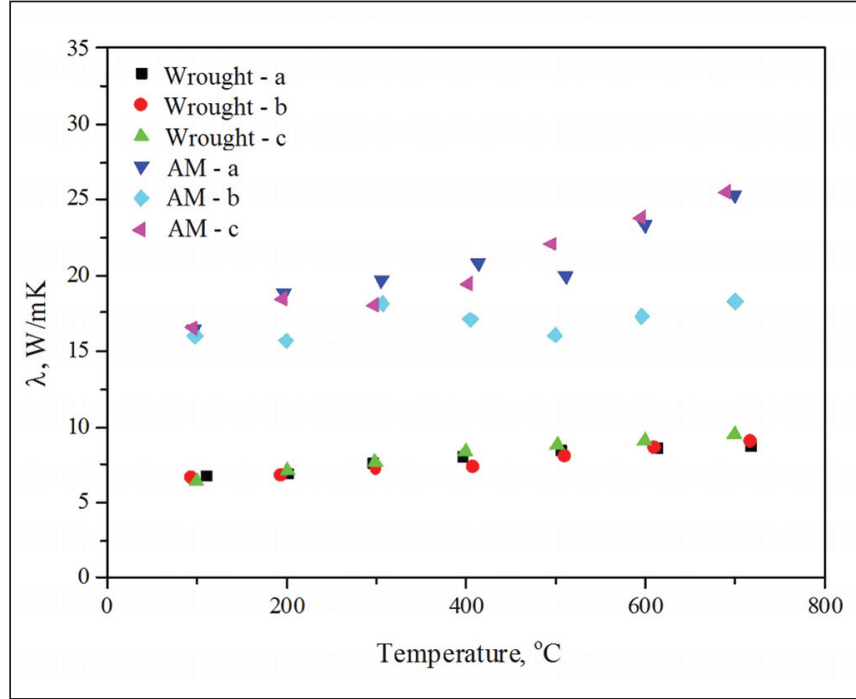

Fig. 4 - Thermal conductivity ( $\lambda$ ) of AM and wrought Ti6Al4V.

The results in Table 5 indicate welding was performed in the conduction mode.

\section{Electron Beam Welding of the Test Parts}

Electron beam welding was performed with a ProBeam $\mathrm{K}-140$ system. The welding parameters used to weld the joints are presented in Table 6 . Similar welding parameters were used for AM and wrought samples.

\section{Thermal Conductivity Measurements}

Veiga et al. (Ref. 21) published that in a wrought Ti6Al4V alloy, the thermal conductivity (TC) varies from about 6.6 to $6.8 \mathrm{~W} / \mathrm{mK}$ at near room temperature to about 16 to 19

$\mathrm{W} / \mathrm{mK}$ at $800^{\circ} \mathrm{C}$. To investigate the differences between $\mathrm{AM}$

\section{Table 4- Laser Beam Welding Parameters}

Laser Power (W)

3000

Welding Speed $(\mathrm{mm} / \mathrm{s})$
Ramp-Up Time (s)

0.5

Optical Fiber

Diameter $(\mathrm{mm})$
Power Hold (s)

Ramp-Down Time (s)
0.5

Focused Beam
2.876
Spatial Profile of the Focused Laser Beam

Beam Focus Position

101.66

0.3

0.5

Top hat

On the part surface

Table 5 - Power Density and Aspect Ratio (AR) for Laser Welding

Group III AM to AM

Group V AM to Wrought

Group VII Wrought

w - Bead width (mm)

2.13

1.89

1.75

I- Power density $\left(\mathrm{W} / \mathrm{mm}^{2}\right)$

$1.32 E+03$

$1.67 E+03$

$1.95 E+03$ 


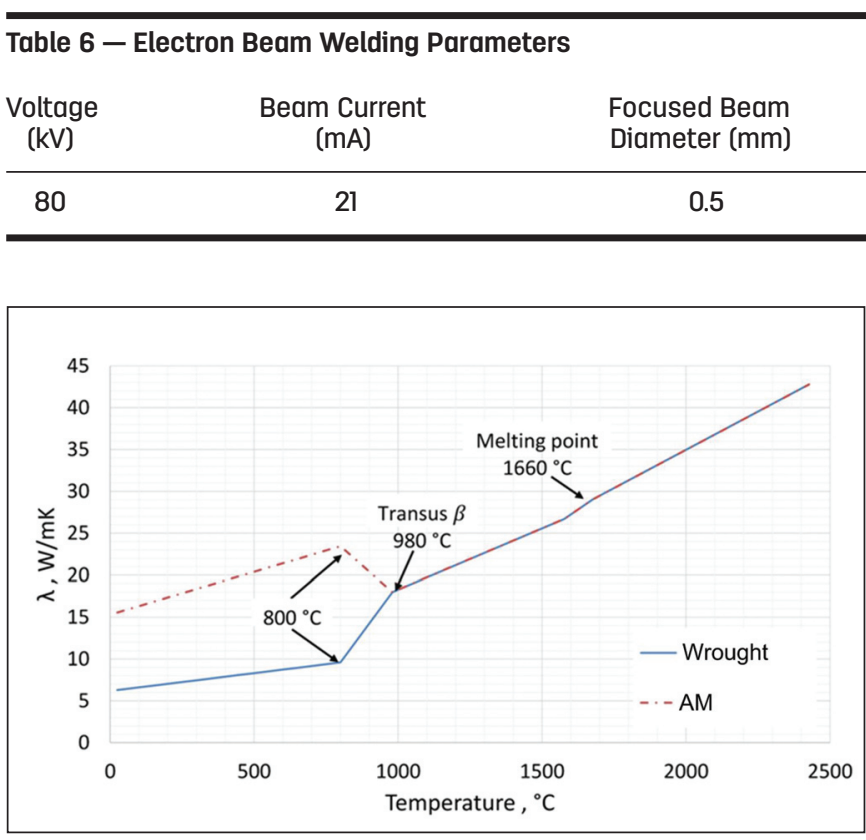

Fig. 5 - Combined plot of thermal conductivity $(\lambda)$.

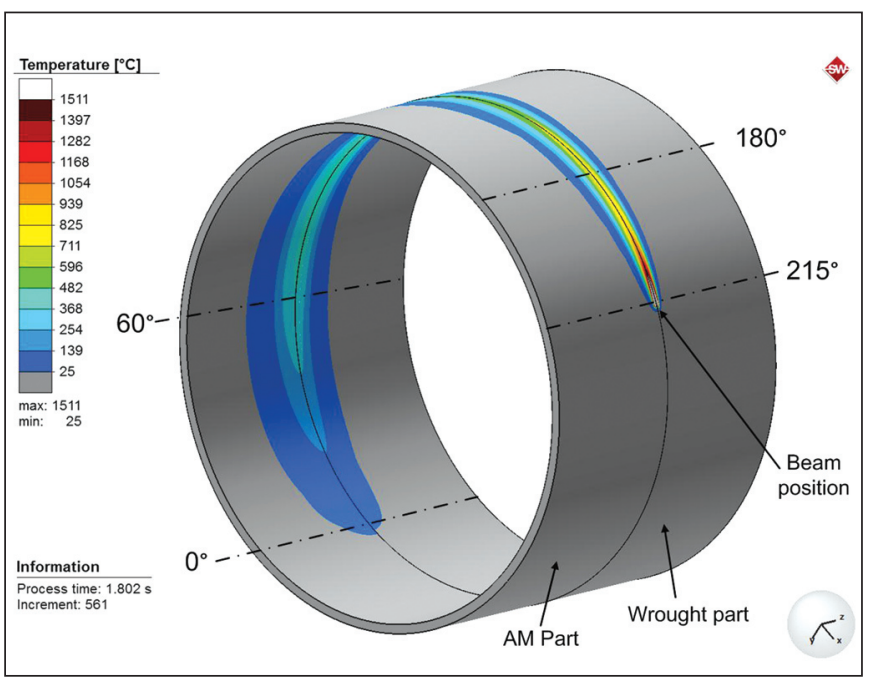

Fig. 6 - Thermal simulation of the LBW process of AM and wrought Ti6Al4V in an intermediate stage of the weld. The laser power was increased from $0 \mathrm{~kW}$ at $0 \mathrm{deg}$ to $3 \mathrm{~kW}$ at 60 deg, kept at the same power level up to $400 \mathrm{deg}$, and then decreased gradually to $0 \mathrm{~kW}$ at an additional $60 \mathrm{deg}$. The color change on both sides of the weld represents the temperature distribution.

and wrought Ti6Al4V, the TC of three specimens $(\varnothing 4$ and 15 mm height) of each material (wrought and AM Ti6Al4V) were measured. The TC measurements were carried out from room temperatures up to $800^{\circ} \mathrm{C}$ utilizing a custommade instrument per the ASTM E1225-13 standard (Ref. 22). The measurements were carried out in steps of $100^{\circ} \mathrm{C}$ increments, with a 1.5-h isothermal hold at each temperature in a vacuum environment. The data collected for each specimen is presented in Fig. 4. The wrought Ti6Al4V specimens displayed good measurement repeatability, while the AM specimen measurements were more scattered.
The TC data measured for both wrought and AM Ti6Al4V in the temperature range of $0^{\circ}$ to $800^{\circ} \mathrm{C}$ were fitted to a linear curve represented by Equations 3 and 4 . The extrapolated higher temperatures are given by Equations 5 and 6 .

$A M: \lambda\left[\frac{w}{m K}\right]=15.31+10.2 \cdot 10^{-3} \cdot T \quad 0<T<800\left[{ }^{\circ} \mathrm{C}\right]$

Wrought: $\lambda\left[\frac{w}{m K}\right]=6.19+4.3 \cdot 10^{-3} \cdot T \quad 0<T<800\left[{ }^{\circ} \mathrm{C}\right]$

According to Boivineau et al. (Ref. 23), the linear fit for the $\beta$ phase was found to be

$\lambda\left[\frac{w}{m K}\right]=3.67+14.6 \cdot 10^{-3} \cdot T \quad 1127<T<1577\left[^{\circ} \mathrm{C}\right]$

And for the liquid phase

$\lambda\left[\frac{w}{m K}\right]=-1.639+18.3 \cdot 10^{-3} \cdot T \quad 1677<T<2427\left[^{\circ} \mathrm{C}\right]$

Making reference to the $\beta$ transus $\left(980^{\circ} \mathrm{C}\right.$ ) of the different materials, the thermal properties due to phase change have been consequently shifted to coincide with the transition area. Figure 5 describes the combined information we measured (Equations 3 and 4) and the data presented by Boivineau et al. (Ref. 23) (Equations 5 and 6) with the appropriate linear shifts.

\section{LBW Simulation}

A three-dimensional finite element model was developed to simulate the LBW process using Simufact Welding, Version 6 (MSC Software Co., Munich, Germany). The goal was to validate and explain the experimental findings. The TC data used in the LBW simulation is shown in Fig. 5. To simulate the LBW process, the energy input from the laser was divided into surface and volumetric heat sources.

The welding process starting position was marked as 0 deg. The laser beam started a linear ramp-up while the tube was rotating, until it reached the full welding power of $3 \mathrm{~kW}$ at $60 \mathrm{deg}$. The laser power was maintained constant for an additional $340 \mathrm{deg}$, until a linear ramp-down started for an additional 60 deg. Figure 6 shows the beam at $215 \mathrm{deg}$ while the thermocouples were located at $180 \mathrm{deg}$ at distances of 1 , 2 , and $3 \mathrm{~mm}$ from the weld interface on both sides symmetrically. 


\section{Microhardness and Oxygen Level Measurements}

Microhardness measurements were carried out using a Future-Tech microhardness tester (FM800) with a 1-kg load for $10 \mathrm{~s}$. Measurements were performed according to the ISO 22826 standard (Ref. 24) as shown in Fig. 7. The oxygen level in the base metal (BM) and fusion zone (FZ) were measured for the electron beam and laser beam welds to support the hardness results. All measurements were performed using x-ray photoelectron spectroscopy (XPS) ESCALAB 250 on wrought and AM materials.

\section{Tensile Tests Measurements}

Tensile tests measurements were carried out with a loading rate of $0.12 \mathrm{~mm} / \mathrm{min}$, with tensile test specimens taken from each group (Table 3 ); the weld bead was oriented transversely to the applied load as shown in Fig. 8. To examine the effect of heat treatment after welding, half of each tensile test specimen group was stress relieved for $3 \mathrm{~h}$ at $650^{\circ} \mathrm{C}$ in a vacuum and then furnace cooled.

\section{Results and Discussion}

\section{Destructive Tests}

Weld bead geometry and thermal behavior. The cross sections of the welded samples were analyzed utilizing an optical stereomicroscope (SMZ800) with modified Kroll's reagent as the etchant. The cross section (presented in Fig. 9C) revealed differences between the wrought and the AM sides of the weld joint's HAZ. The HAZ of the wrought sides has a fine-grained region that is not seen on the AM side. As seen in Figs. 7 and 9, the wrought BM has fine grains, while the AM BM has coarse grains. Due to the high cooling rate in LBW and EBW, the size of the grains in the HAZ had minor changes compared to the BM region.

In addition, the cross section (presented in Fig. 9C) revealed a significant difference in the FZ boundary when a wrought material was laser welded to an AM material. This phenomenon did not exist when two compatible materials were laser welded, as shown in Fig. 9A and E. The FZ boundary in LBW on the AM material side of the joint was wider and had a straight shape compared to the neck-shaped fusion boundary of the weld of the wrought material. Laitinen (Ref. 25) observed a similar phenomenon during welding of AM to wrought stainless steel sheet. He speculated the difference in the fusion zone boundaries might have derived from the initially lower-molten pool viscosity of the AM sheet vs. wrought sheet metal, and from the differences in weld pool viscosities and material flows in a molten weld. In the following paragraphs, we propose a different explanation of this phenomenon.

Figure 5 shows the TC of wrought and AM materials. It is important to note that, up to $800^{\circ} \mathrm{C}$, the TC of the AM material was about 2.5 times as high as that of the wrought material; these results may explain the difference in the weld bead geometry between the materials. The heat transferred faster in the AM material, resulting in a wider FZ and HAZ

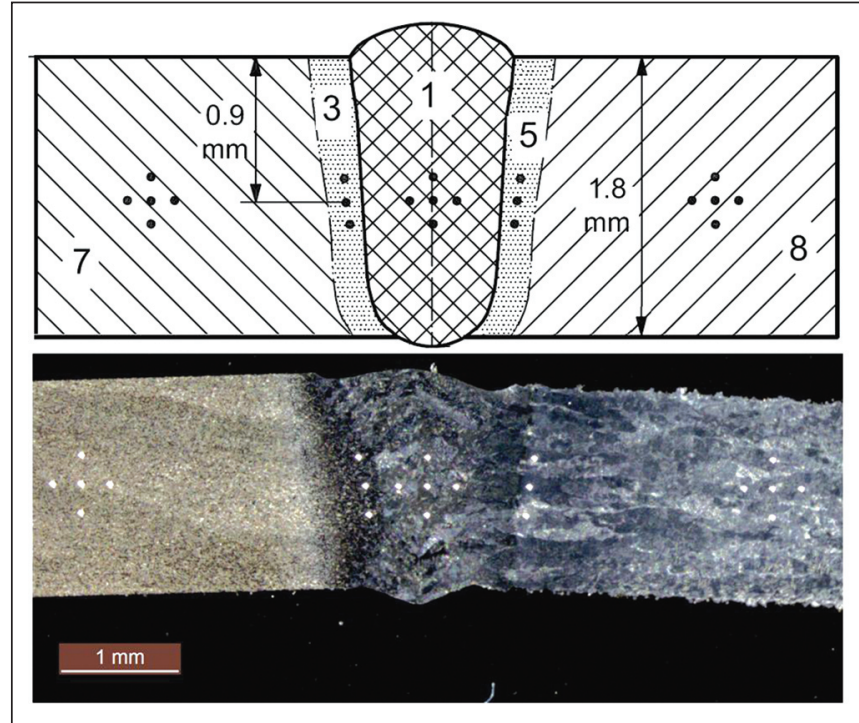

Fig. 7 - Location of group indentations for hardness testing. Key numbers: 1 - Weld metal; 3, 5 - HAZ; 7, 8 - base metal.

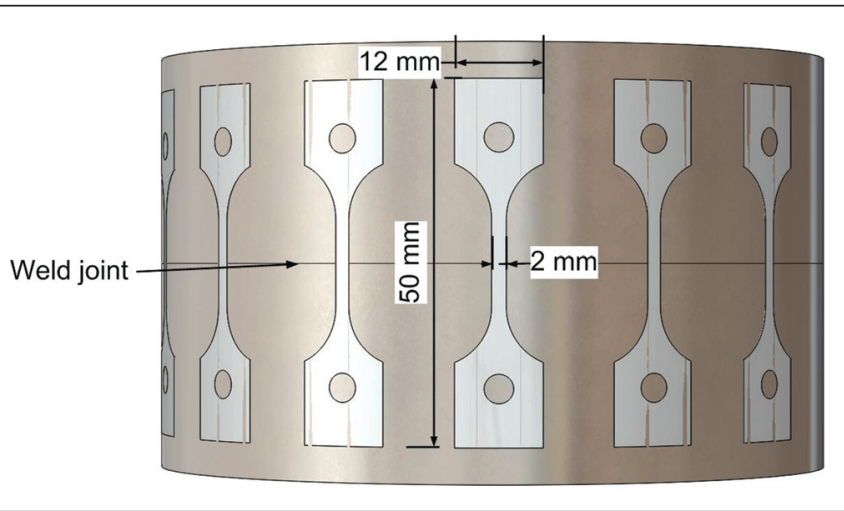

Fig. 8-Geometry of tensile test pieces.

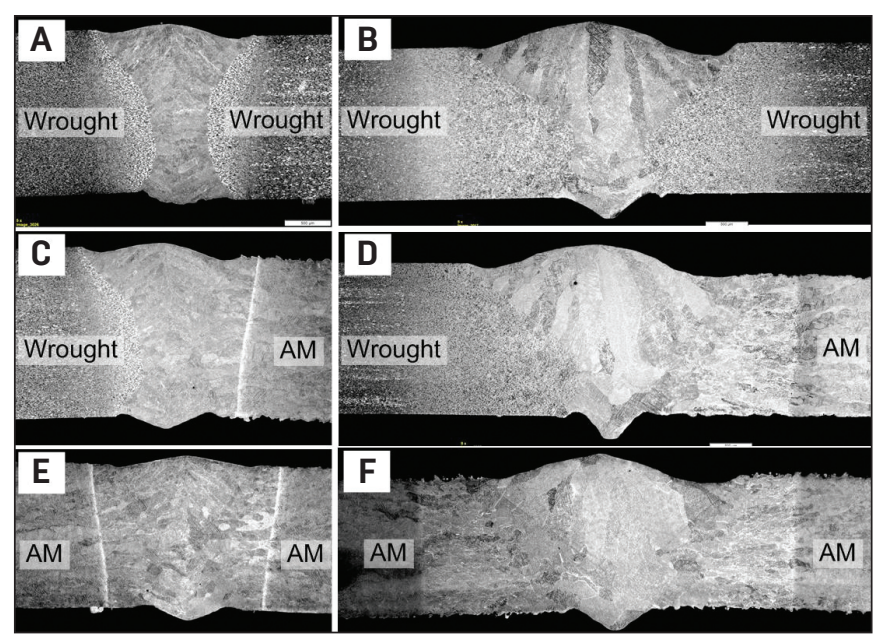

Fig. 9 - Weld cross sections: $A$ - LBW of wrought materials; $B-E B W$ of wrought materials; $C-L B W$ of AM to wrought materials; $D-E B W$ of AM to wrought materials; $E-L B W$ of AM materials; $F-E B W$ of $A M$ materials. 


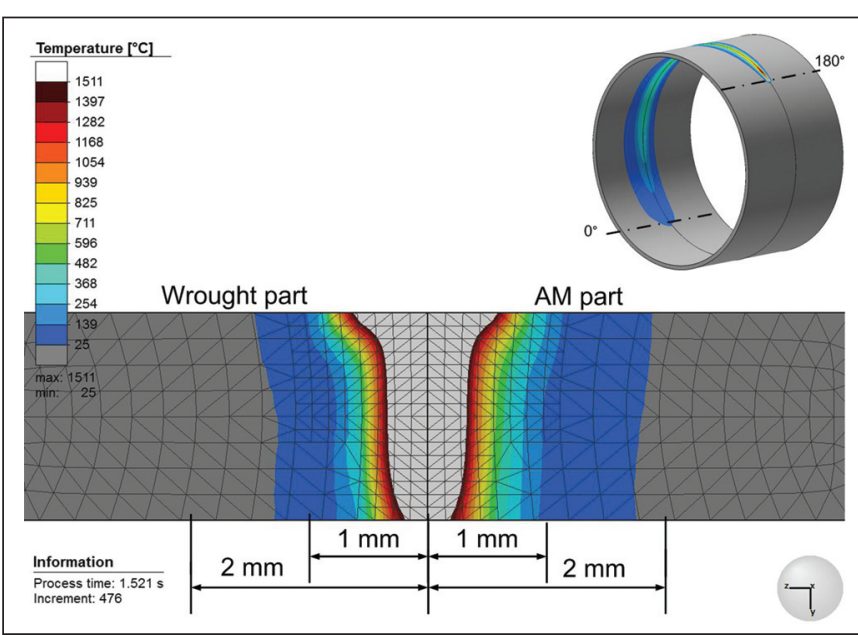

Fig. 10 - Temperature distribution for heat input and beam position at $180 \mathrm{deg}$. The difference in thermal conductivity (Fig. 5) creates asymmetrical thermal gradients across the weld. (Thermocouple positions: Internal ring surface at 1, 2, and $3 \mathrm{~mm}$ from each side of the weld interface.)

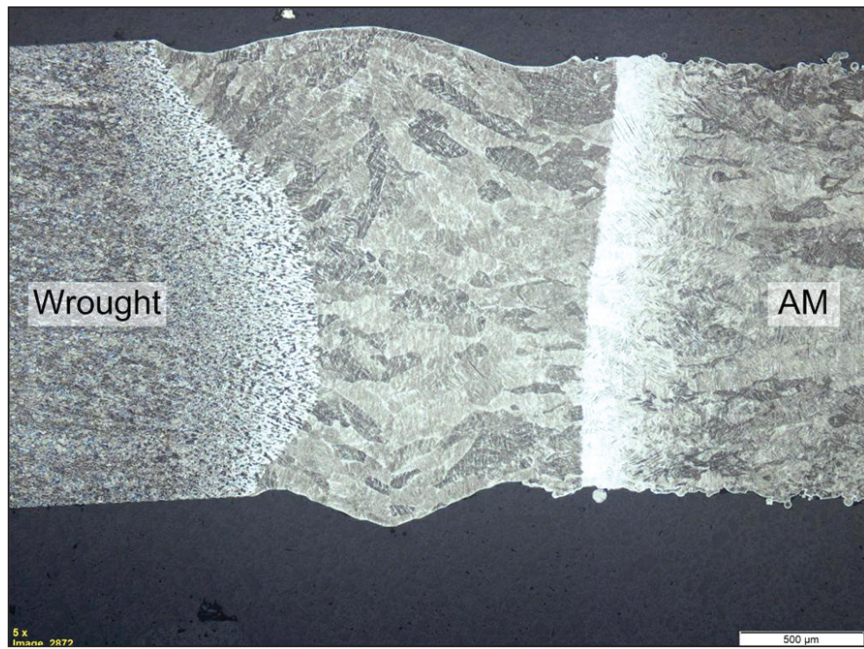

Fig. 11 - Cross section of AM to wrought Ti6Al4V LBW: Asymmetrical fusion zone boundary.

than in the wrought material. Ti6Al4V can be heat treated to give a wide variety of microstructures with a diversity of mechanical and physical properties. The differences in TC between the wrought mill-annealed Ti6l4V (with $\alpha / \beta$ ) and SLM AM with an $\alpha^{\prime}$ microstructure (Ref. 26) are not necessarily unusual. The same differences in conductivity are likely to be seen if the samples have been heat treated to produce the same types of microstructures. For example, if the SLM AM sample is heat treated to produce the mill-annealed microstructure, it would likely have a TC similar to that of the wrought material. The difference in microstructure between the wrought and AM parts results from variance in the manufacturing process's cooling rates, which influences the TC. The influence of the microstructure on the TC is illustrated by the comparison between the AM Ti6Al4V TC (Equation 3) and pure titanium, which has a TC of 21 to 22 $\mathrm{W} / \mathrm{mK}$ (Ref. 21). Both materials have a similar $\alpha$-phase microstructure and, as a result, a similar TC.

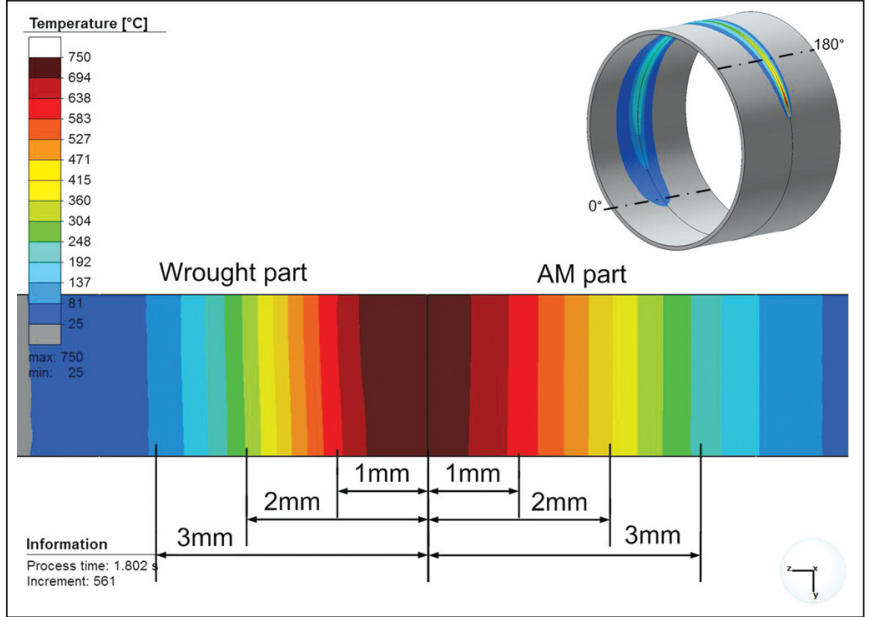

Fig. 12 - Temperature distribution cross section at 180 deg when the laser beam position reached 215 deg (0.28 s later). Thermocouple positions: Internal ring surface at 1,2 , and 3 $\mathrm{mm}$ from each side of the weld interface.

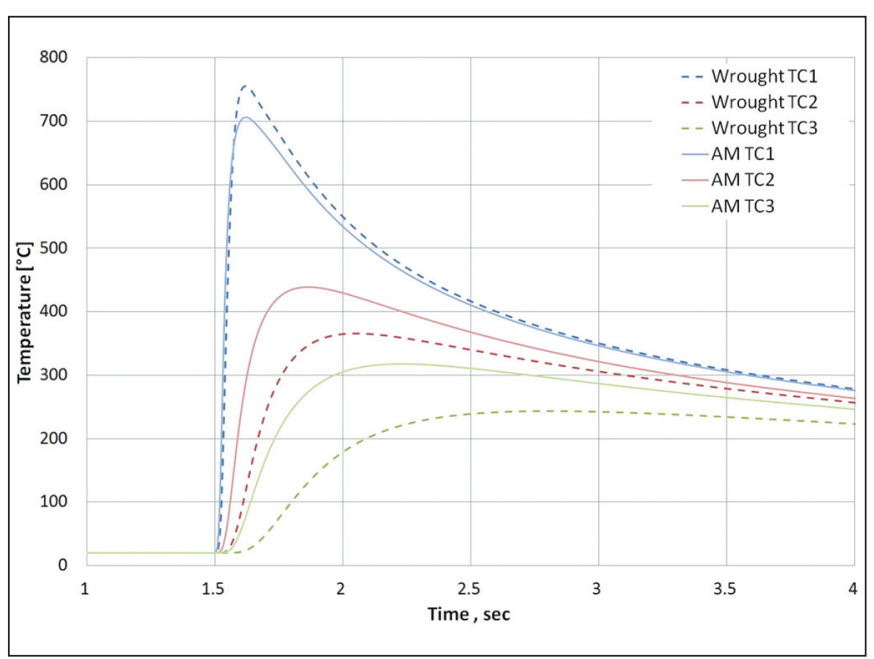

Fig. 13 - Temperature variation versus time for given materials: - Solid lines: wrought material; dashed lines: AM material. Temperatures measured at 1 (TC1), 2 (TC2), and 3 (TC3) $\mathrm{mm}$ from the weld interface at an angle of $180 \mathrm{deg}$ from the weld origin.

The facilities used to measure the TC allowed us to conduct measurements up to $800^{\circ} \mathrm{C}$. The relatively high value of $\mathrm{TC}$ for the AM titanium alloy obtained in the $25^{\circ}$ to $800^{\circ} \mathrm{C}$ temperature range reflects its crystal structure, namely the high fraction of $\alpha$ phase. For higher temperatures, we applied a linear extrapolation, as seen in Equations 5 and 6 as well as Fig. 5.

During welding, a local narrow zone is heated by the laser beam; the material is melted and partially vaporized, and it then rapidly solidifies. The elevated temperature gradients along and across the weld affect the mechanical properties and microstructures. As long as the weld is between two similar materials, it is expected to achieve symmetry in heat transfer and mechanical properties across the weld. When welding wrought to AM Ti6Al4V, the thermal properties are different and heat transfers differently in each material - Figs. 10-13. 

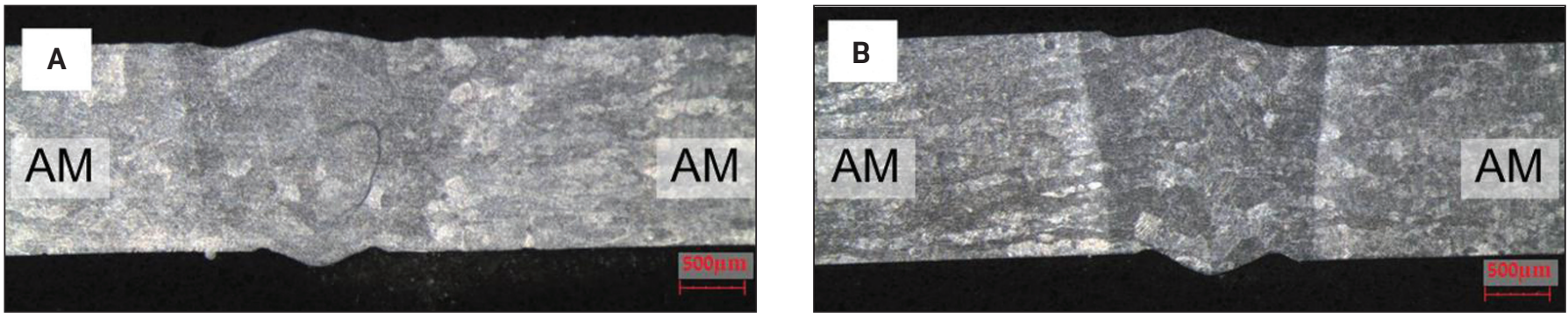

Fig. 14 - Effect of surface roughness on LBW cross sections of AM material: A - Weld of as-built material; B - weld of surfacemachined material.

Figure 10 shows the finite element mesh used in the simulation, as well as the temperature distribution at a cross section located at $180 \mathrm{deg}$ when the laser beam is also positioned at 180 deg. Figure 11 presents a cross section of a specimen with dissimilar welded materials. The simulated temperature distribution shown in Fig. 10 and the welded geometry shown in Fig. 11 reveal a similar pattern. This may explain how the difference in TC creates a unique bead geometry pattern in LBW between AM and wrought materials. Figure 12 shows the simulated temperature distribution at the same cross section (at $180 \mathrm{deg}$, where the thermocouples were placed) when the beam reaches $215 \mathrm{deg}$. The simulated temperatures as a function of time for each thermocouple are presented in Fig. 13. The thermocouples TC1, located at $1 \mathrm{~mm}$ from both sides of the weld joint, measured the maximum temperature, which was approximately $45^{\circ} \mathrm{C}$ higher in the wrought material than in the AM one. The AM material resulted in a higher temperature than the wrought material when the distance was farther than approximately $1.1 \mathrm{~mm}$ from the weld joint. At all positions, the measured temperatures were almost similar after approximately $3.5 \mathrm{~s}$.

Testing the effect of additive manufactured surface roughness on bead geometry. To validate whether the surface roughness (Fig. 16) affects laser beam emissivity and thus the weld cross-section profile, LBW tests were performed on a machined AM surface (Group IX). The cross section of the weld is shown in Fig. 14; the same results were found in machined and as-built AM welded samples. The results indicate the surface roughness had no significant effect on the weld shape, and the emissivity change due to surface roughness had a minor effect on the AM LBW.

Microhardness and oxygen level tests. Microhardness measurements were performed for all of the welds; the results for each manufacturing process are shown in Table 7. On wrought Ti6Al4V EBW and LBW, the microhardness of the $\mathrm{FZ}$ was higher than that of the BM counterpart due to the formation of an $\alpha$ martensitic phase in the FZ. The HAZ consisted of a mixture of $\alpha$ martensite and primary $\alpha$ phases (Refs. 27, 28). AM Ti6Al4V microhardness was higher than that of wrought Ti6Al4V by approximately $35 \mathrm{HV}$. The hardness of AM Ti6Al4V was higher because the melt pool cools down very rapidly during the SLM process after the laser beam has passed. Hence, fast cooling gives rise to a martensitic $\alpha$ ' phase (Ref. 29).

In electron beam welds, the oxygen level was higher in the BM than in the FZ. In wrought Ti6Al4V, the oxygen level was $0.099 \%$ in the BM and $0.080 \%$ in the FZ. In AM

Ti6Al4V, the oxygen level was $0.051 \%$ in the BM and $0.047 \%$

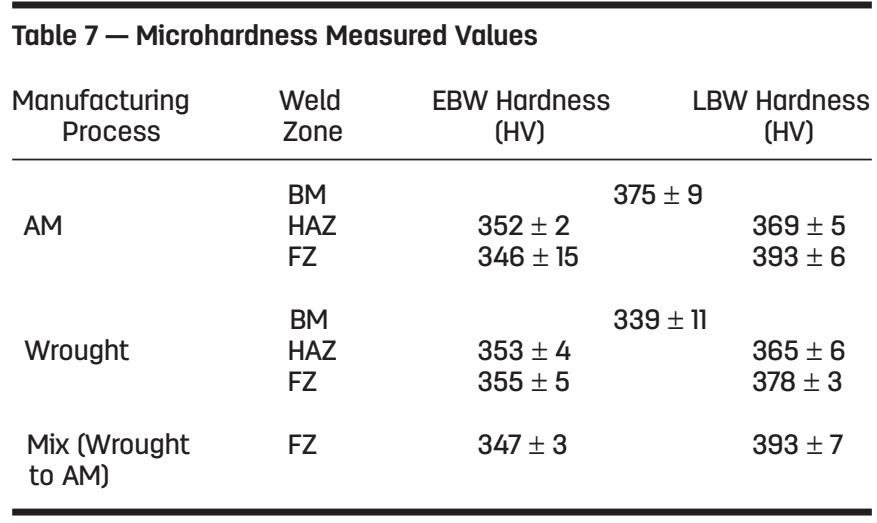

in the $\mathrm{FZ}$, and vice versa in laser beam welds. In wrought Ti6Al4V, the oxygen level was $0.081 \%$ in the BM and $0.086 \%$ in the FZ. In AM Ti6Al4V, the oxygen level was $0.039 \%$ in the $\mathrm{BM}$ and $0.043 \%$ in the $\mathrm{FZ}$.

The microhardness of laser beam welds is higher than that of EBW welds for both AM and wrought material welds. More oxygen is absorbed during LBW because EBW is performed in a high vacuum (hence almost no oxygen absorption). Another reason for the difference in microhardness is the faster cooling rate in LBW compared to EBW; during LBW, the welding speed is faster, and so is the convective cooling. For EBW of AM Ti6Al4V, the microhardness of the FZ is lower than that of the BM due to the controlled environment and slower cooling rate in the EBW process (without convective cooling) vs. the cooling rate in the AM manufacturing process.

Tensile properties tests. Wrought Ti6Al4V products are used predominantly in a mill-annealed or solution-treated and aged condition with typical tensile properties of $\sigma_{\mathrm{y}}=$ 850-1050 MPa, $\sigma_{\text {UTS }}=950-1200 \mathrm{MPa}$, and elongation values of 10 to $15 \%$ (Ref. 30). With regard to the effect of cooling rate on ductility, Yung at el. (Ref. 31) found that the higher the cooling rate, the larger the relative elongation and, hence, the higher the ductility of the weld.

The mechanical properties for all nonheat-treated samples vs. the heat-treated specimens are presented in Fig. 15. The results show that AM Ti6Al4V (Group I) has a higher tensile strength and a significant decrease in ductility compared to wrought Ti6Al4V (Group II). The differences between the materials rely on the hexagonal close-packed (HCP) martensitic microstructure of AM laser-melted materials, which renders a higher tensile strength and a lower ductility (Ref. 3). All of the welded test specimens were 

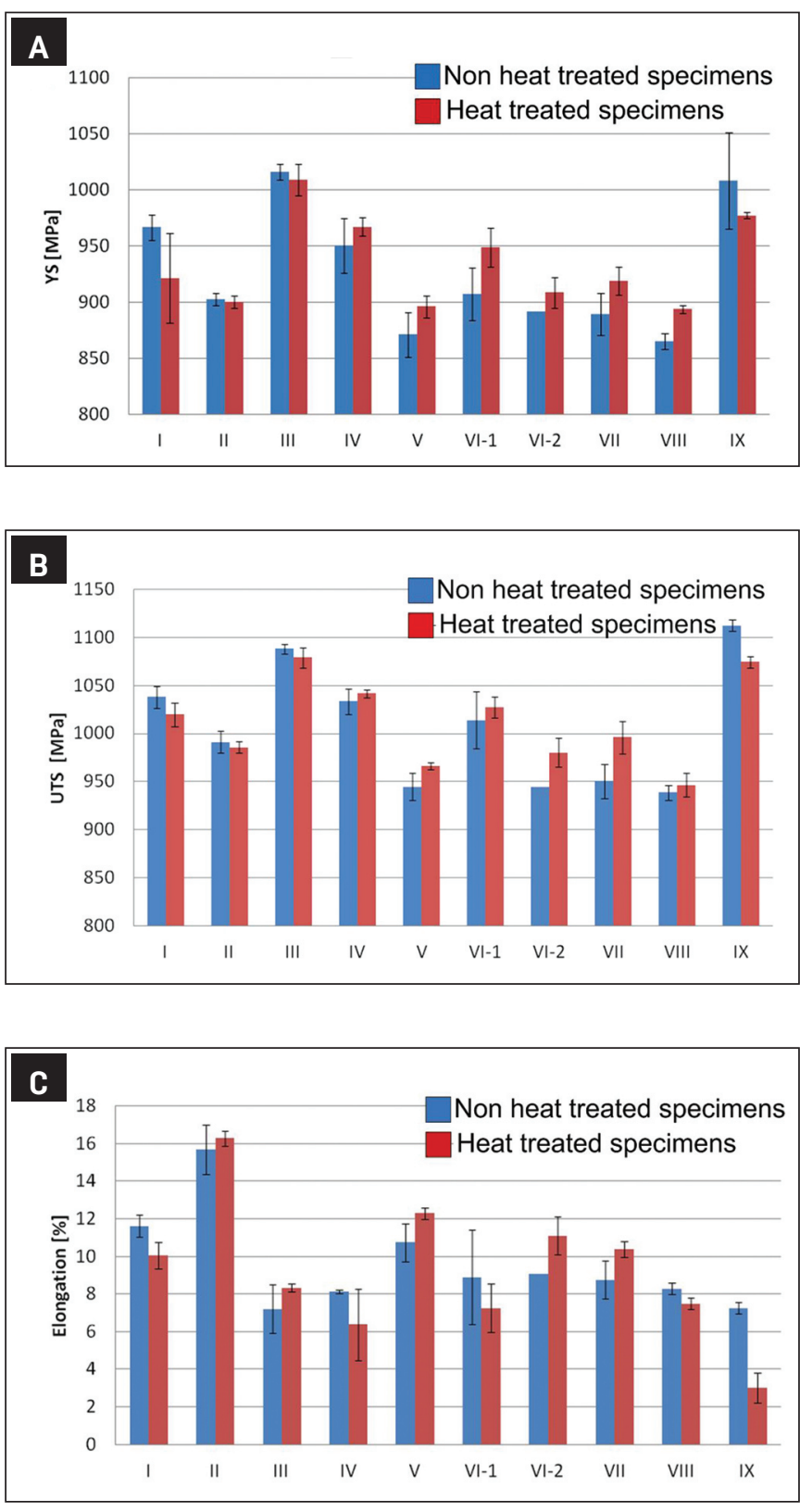

Fig. 15 - Tensile test results: A - Yield strength (YS); B - ultimate tensile strength (UTS); $\mathrm{C}$ - elongation.

fractured in the BM. Test specimens with combined material conditions (AM and wrought) were fractured in the wrought material BM. LBW of AM (Group III) had a higher tensile strength than EBW of AM (Group IV). Postprocess heat treatment after welding increased the tensile strength of welds, which included wrought material (Groups V-VIII). All AM specimens underwent heat treatment prior to removal from the building platform; therefore, the reheat treatment after welding had no significant effect on the tensile strength.

\section{Nondestructive Tests}

AWS D17.1, Specification for Fusion Welding of Aerospace Applications (Ref. 32), specifies the requirements for welding
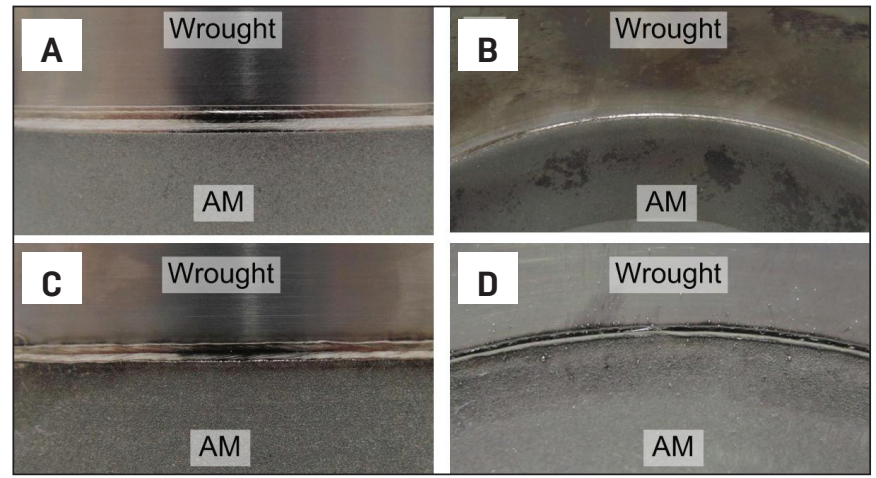

Fig. 16 - Visual inspection, wrought to AM Ti6Al4V welds: A EBW face surface (external surface); $B-E B W$ root surface (internal surface); $C$ - LBW face surface; $D-L B W$ root surface.
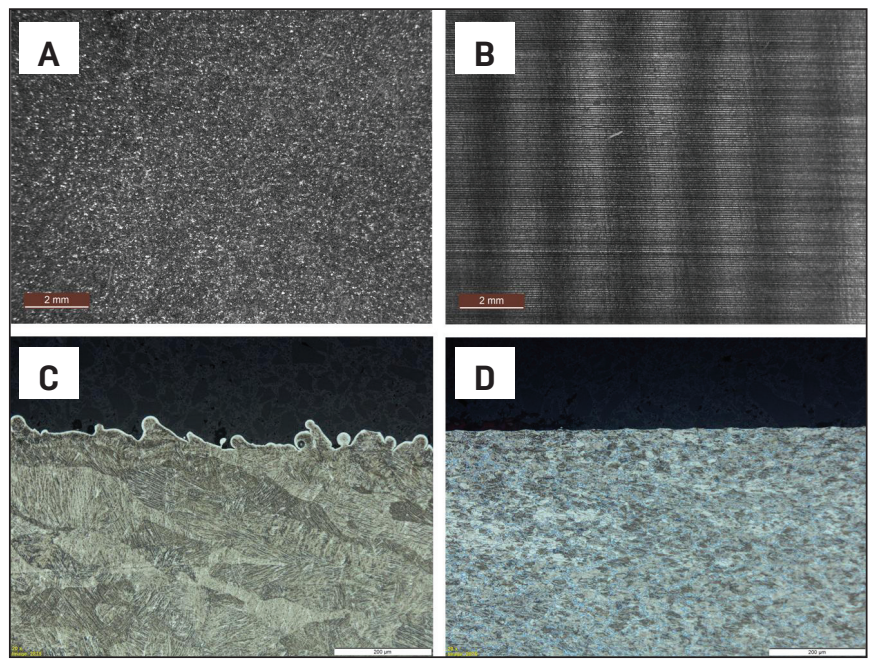

Fig. $17-A-$ Surface roughness of AM material; $B$ - surface roughness of wrought material; $C$ - cross section of $A M$ material; $D$ - cross section of wrought material.

aircraft and space hardware of titanium alloys and other metallic materials. It covers electric arc, plasma arc, oxyfuel, laser beam, and electron beam welding processes. However, according to Engel (Ref. 20), AWS D17.1 is an internationally accepted standard, but it does not include laser welding or the laser welding of titanium. The ISO 13919-1 (Ref. 33) standard does not cover titanium alloys, but it does provide guidelines for laser weld profile and quality definitions especially for "stringent quality" welds. Both the AWS D17.1 and the ISO 13919-1 standards were used for performing nondestructive testing (NDT) of the welded parts. Each welded specimen was examined by visual testing, dye penetration (ultraviolet dye penetration), and x-ray (microfocus system).

Visual inspection of the welds showed both weld materials had no spatter on the face surface and very little spattering near the weld root face, whereas LBW showed slightly more spatter than EBW - Fig. 16. In the LBW samples, there was a minor color change near the weld, whereas no color change was noticed in the EBW samples. There is no specific standard for color change of LBW of titanium alloys; 

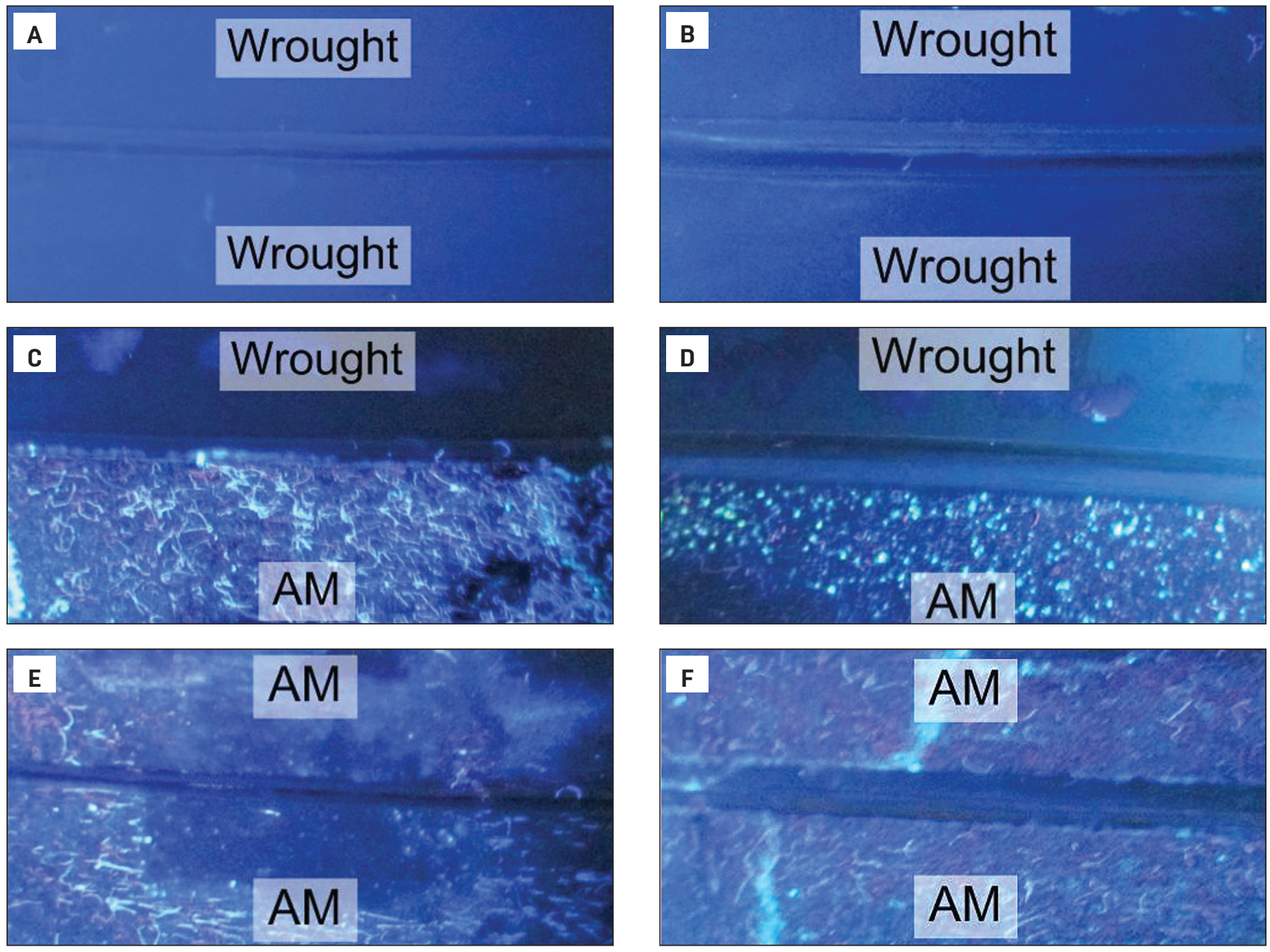

Fig. 18 - Fluorescent dye penetrant inspection results: $A$ - LBW of wrought materials; $B$ - EBW of wrought materials; $C$ - LBW of wrought to AM materials; $D$ - EBW of wrought to AM materials; $E$ - LBW of AM materials; $F-E B W$ of AM materials.

Engel (Ref. 20) published in his guidelines that no color change is permitted in LBW. However, according to the AWS D17.1 standard recommendation, some color change is allowed. To verify the minor color change had no influence on weld metallurgical properties, the weld cross section was examined for the presence of $\alpha$ case - a continuous, hard, and brittle layer that significantly reduces several important mechanical properties of titanium alloys (Ref. 34) - and no evidence of it was found. As a result, both welding methods (EBW and LBW) fulfill the AWS D17.1 and ISO 13919-1 standards requirements.

Due to the rough surface of the AM material (Fig. 17), dye penetrant examination was applicable only for wrought welded materials, whereas for the AM material the dye penetrant could not be fully removed from the surface (by solvent). When the developer was applied, it drew the dye penetrant from the AM material surface, and thus impeded the ability to distinguish surface defects near the weld (Fig. 18).

The $\mathrm{x}$-ray inspection showed almost no porosity in EBW and very few pores in LBW. All of the welds were inspected according to the AWS D17.1 and ISO 13919-1 standards, and met the specifications of both standards.

\section{Conclusions}

The welding quality of Ti6Al4V additive manufactured (AM) parts was compared to the welding quality of wrought manufactured parts. The welding was performed using highpower fiber laser beam welding (LBW) and electron beam welding (EBW) processes. Results show there are certain differences in the welded joints of AM parts compared to wrought parts.

The following conclusions were drawn from this study:

1) The fusion zone boundary in the AM material is wider and has a relatively straight shape compared to the neckshaped weld interface in the wrought material. The HAZ is larger in the AM material.

2) The thermal conductivity of the AM material is about 2.5 times as high as that of the wrought material.

3) Finite element simulation supported and explained the asymmetry in the temperature distributions and the experimental results. The fusion zone is wider in the AM material than in the wrought material.

4) AM Ti6Al4V has a higher tensile strength but a significantly lower ductility than wrought Ti6Al4V. 
5) LBW of AM produces a higher tensile strength than EBW of AM.

6) The weld hardness of LBW is higher than the hardness of EBW for both AM and wrought Ti6Al4V welds.

7) All of the weld test specimens were fractured in the base metal, indicating that geometrical defects had no effect and that good quality joints were obtained. Test specimens with combined material conditions (AM and wrought) were fractured in the wrought material base metal.

8) Heat treatment after welding increased the tensile strength of welds in wrought material.

9) Due to the surface roughness of AM parts, cleaning with a cheesecloth is not recommended. The cheesecloth fibers remain attached to the part's rough surface and can cause porosity.

10) Dye penetrant inspection is possible only with wrought welded materials. Due to the rough surface quality of the AM material, the dye cannot be fully removed from the surface (by solvent).

This study has demonstrated that it is possible to weld AM parts to each other and to wrought Ti6Al4V parts, as well as that it is possible to achieve good-quality welds using either LBW or EBW processes. Future research will address the temperature distribution during LBW of additively manufactured versus wrought Ti6Al4V, and the effect of the material thickness on the weld.

\section{Acknowledgments}

The authors would like to warmly acknowledge Simon L. Engel of HDE Technologies Inc. for his consulting and support. The authors also wish to thank O. Dolev for his beneficial advice and help in preparing the AM samples; the people at Rafael Metal Technology Center, A. Uziel of the metallurgical department; and N. Frage of the materials department at Ben-Gurion University of the Negev for their technical assistance in the performance and examination of the welds.

\section{References}

1. Huang, S. H., Liu, P., and Mokasdar, A. 2013. Additive manufacturing and its societal impact: A literature review. International Journal of Advanced Manufacturing Technology 67: 1191-1203. DOI: 10.1007/s00170-012-4558-5.

2. Gibson, I., Rosen, D. W., and Stucker, B. 2010. Rapid Prototyping to Direct Digital Manufacturing. London: Springer, pp. 42-65. DOI 10.1007/978-1-4419-1120-9.

3. Gu, D. D., Meiners, W., Wissenbach, K., and Poprawe, R. 2012. Laser additive manufacturing of metallic components: Materials, processes and mechanisms. International Materials Reviews 57: 133-164. DOI: 10.1179/ 1743280411 Y.0000000014.

4. Atzeni, E., and Salmi, A. 2012. Economics of additive manufacturing for end-usable metal parts. International Journal of Advanced Manufacturing Technology 62: 1147-
1155. DOI 10.1007/s00170-011-3878-1.

5. Herderick, E. 2011. October 16-20, 2011. Additive manufacturing of metals: A review. MS\&T 2011: Proceedings from the Materials Science \& Technology Conference, 14131425. Columbus, Ohio: ASM International.

6. Matilainen, V.-P., Pakkarinen, J., and Salminen, A. 2016. Weldability of additive manufactured stainless steel. Physics Procedia 83: 808-817. DOI: 10.1016/j.phpro.2016. 08.083 .

7. Wits, W., and Becker, J. J. 2015. Laser beam welding of titanium additive manufactured parts. Procedia CIRP 28: 70-75. DOI: 10.1016/j.procir.2015.04.013.

8. Casalino, G., Campanelli, S. L., and Ludovico, A. D. 2013. Laser-arc hybrid welding of wrought to selective laser molten stainless steel. International Journal of Advanced Manufacturing Technology 68: 209-216. DOI: 10.1007/ s00170-012-4721-z.

9. Nahmany, M., Rosenthal, I., Benishti, I., Frage, N., and Stern, A. 2015. Electron beam welding of AlSi10Mg workpieces produced by selected laser melting additive manufacturing technology. Additive Manufacturing 8: 63-70. DOI: https://doi.org/10.1016/j.addma.2015.08.002.

10. Prashanth, K., Damodaram, R., Scudino, Z. W. S., Rao, K. P., and Eckert, J. 2014. Friction welding of Al-12Si parts produced by selective laser melting. Materials and Design 57: 632-637. DOI: http://dx.doi.org/10.1016/j. matdes.2014.01.026.

11. Dutta, B., and Froes, F. H. 2016. Additive Manufacturing of Titanium Alloys. London: Elsevier. DOI: http://dx.doi. org/10.1016/B978-0-12-804782-8.00001-X.

12. Wang, S., and Wu, X. 2012. Investigation on the microstructure and mechanical properties of Ti-6Al-4V alloy joints with electron beam welding. Materials and Design 36: 663-670. DOI: 10.1016/j.matdes.2011.11.068.

13. Balasubramanian, T. S., Balakrishnan, M., Balasubramanian, V., and Manickam, M. A. M. 2011. Influence of welding processes on microstructure, tensile and impact properties of Ti-6Al-4V alloy joints. Transactions of Nonferrous Metals Society of China 21: 1253-1262. DOI: 10.1016/ S1003-6326(11)60850-9.

14. Blackburn, J. 2012. Laser welding of metals for aerospace and other applications. Welding and Joining of Aerospace Materials. Ed. M. C. Chaturvedi. Oxford: Woodhead, pp. 75-108. DOI: https://doi.org/10.1533/9780857095169. 1.75 .

15. Tsai, C. J., and Wang, L. M. 2014. Improved mechanical properties of Ti-6Al-4V alloy by electron beam welding process plus annealing treatments and its microstructural evolution. Materials and Design 60: 587-598. DOI: http:// dx.doi.org/10.1016/j.matdes.2014.04.037.

16. Saresh, N., Pillai, M. G., and Mathew, J. 2007. Investigations into the effects of electron beam welding on thick Ti-6Al-4V titanium alloy. Journal of Materials Processing and Technology 192: 83-88. DOI: 10.1016/j.jmatprotec.2007. 04.048 .

17. ASTM. 2014. F2924-14, Standard Specification for Additive Manufacturing Titanium-6 Aluminum-4 Vanadium with Powder Bed Fusion. West Conshohocken, Pa.: ASTM International. DOI: 10.1520/F2924.

18. SAE International. 2015. AMS4904C: Titanium Alloy Sheet, Strip, and Plate, $6 \mathrm{Al}-4 \mathrm{~V}$, Solution Heat Treated and 
Aged. Warrendale, Pa.: SAE International. DOI: https:// doi.org/10.4271/AMS4904C.

19. SAE International. 2014. Welding, Electron-Beam. Warrendale, Pa.: SAE International. DOI: https://doi.org/ 10.4271/AMS2681.

20. Engel, S. L. 2016. Laser Welding Technology: Equipment and Procedure Qualification. Elk Grove, CA: HDE Technologies.

21. Veiga, C., Davim, J., and Loureiro, A. 2012. Properties and applications of titanium alloys: A brief review. Reviews on Advanced Materials Science 32: 133-148.

22. ASTM. 2013. E1225-13, Standard Test Method for Thermal Conductivity of Solids Using the GuardedComparative-Longitudinal Heat Flow Technique. West Conshohocken, Pa.: ASTM International. DOI: 10.1520/E1225.

23. Boivineau, M., Cagran, C., Doytier, D., Eyrand, V., Nadal, M. H., Wilthan, B., and Pottlacher, G. 2006. Thermophysical properties of solid and liquid Ti-6Al-4V (TA6V) alloy. International Journal of Thermophysics 27: 507-529. DOI: https://doi.org/10.1007/PL00021868.

24. ISO. 2005. ISO 22826:2005: Destructive tests on welds in metallic materials - Hardness testing of narrow joints welded by laser and electron beam (Vickers and Knoop hardness tests). Geneva: ISO Copyright Office.

25. Laitinen, V. 2015. Weldability of powder bed fusion fabricated stainless steel 316L sheets to cold rolled sheet metal, pp. 52-57. Lappeenranta, Finland: Lappeenranta University of Technology.

26. Vrancken, B., Thijs, L., Kruth, J. P., and Humbeeck, J. V. 2012. Heat treatment of Ti6Al4V produced by selective laser melting: Microstructure and mechanical properties. Journal of Alloys and Compounds 541: 177-185.

27. Cao, M. X. 2009. Effect of welding speed on butt joint quality of Ti-6Al-4V alloy welded using a high-power Nd:YAG laser. Optics and Lasers in Engineering 47: 12311241. DOI: https://doi.org/10.1016/j.jallcom.2012.07.022.

28. Wang, S., and Wu, X. 2012. Investigation on the microstructure and mechanical properties of $\mathrm{Ti}-6 \mathrm{Al}-4 \mathrm{~V}$ alloy joints with electron beam welding. Materials and Design 36: 663-670. DOI: 10.1016/j.matdes.2011.11.068.

29. Hernandez, D. G. 2014. Mechanical behavior assessment of the Ti6Al4V alloy obtained by additive manufacturing towards aeronautical industry, pp. 37-38. M.S. thesis. Lisbon: Técnico Lisboa.

30. Wanjara, P., Brochu, M., and Jahazi, M. 2005. Ti-6Al$4 \mathrm{~V}$ electron beam weld qualification using laser. Materials Characterization 54: 254-262. DOI:10.1016/j.matchar.2004. 12.002.

31. Yung, W. K., Ralph, B., Lee, W., and Fenn, R. 1997. An investigation into welding parameters affecting the tensile properties of titanium welds. Journal of Materials Processing Technology 63: 759-764. DOI: 10.1016/S0924-0136(96) 02719-7.

32. American Welding Society. 2010. AWS D17.1/ D17.1M:2010-AMD1: Specification for Fusion Welding for Aerospace Applications. Miami, Fla.: American Welding Society.

33. ISO. 1996. ISO 13919-1:1996: Welding - Electron and laser-beam welded joints - Guidance on quality levels for imperfections - Part 1: Steel. Geneva: ISO Copyright Office.

34. Sefer, B. 2014. Oxidation and alpha-case phenomena in titanium alloys used in aerospace industry: Ti-6Al-2Sn4Zr-2Mo and Ti-6Al-4V, p. 31. Luleå, Sweden: Luleå University of Technology. DOI:10.1088/1757-899X/48/1/ 012002. 